\title{
Erratum to: Social relationships, mental health and wellbeing in physical disability: a systematic review
}

Hannah Tough ${ }^{1,2}$, Johannes Siegrist ${ }^{3}$ and Christine Fekete ${ }^{1 *}$

\section{Erratum}

Following publication of this article [1], it has come to our attention that a part of Fig. 1 was included in error. The data "Other (17)" should not be included on the list of "Articles excluded based on abstract screening". The original version of the article has been revised to reflect this.

\footnotetext{
Author details

${ }^{1}$ Swiss Paraplegic Research, Guido A. Zäch Strasse 4, 6207 Nottwil, Lucerne, Switzerland. 'Department of Health Sciences and Health Policy, University of Lucerne, Frohburgstrasse 3, P.O. Box 4466, 6002 Lucerne, Switzerland. ${ }^{3}$ Senior Professorship 'Work Stress Research', Faculty of Medicine, University of Düsseldorf, Life-Science-Center, Merowingerplatz 1a, 40225 Düsseldorf, Germany.
}

Received: 16 May 2017 Accepted: 18 May 2017

Published online: 16 June 2017

\section{Reference}

1. Tough H, Siegrist J, Fekete C. Social relationships, mental health and wellbeing in physical disability: a systematic review. BMC Public Health. 2017;17:1. doi:10.1186/s12889-017-4308-6

\footnotetext{
* Correspondence: christine.fekete@paraplegie.ch

'Swiss Paraplegic Research, Guido A. Zäch Strasse 4, 6207 Nottwil, Lucerne, Switzerland

Full list of author information is available at the end of the article
} 


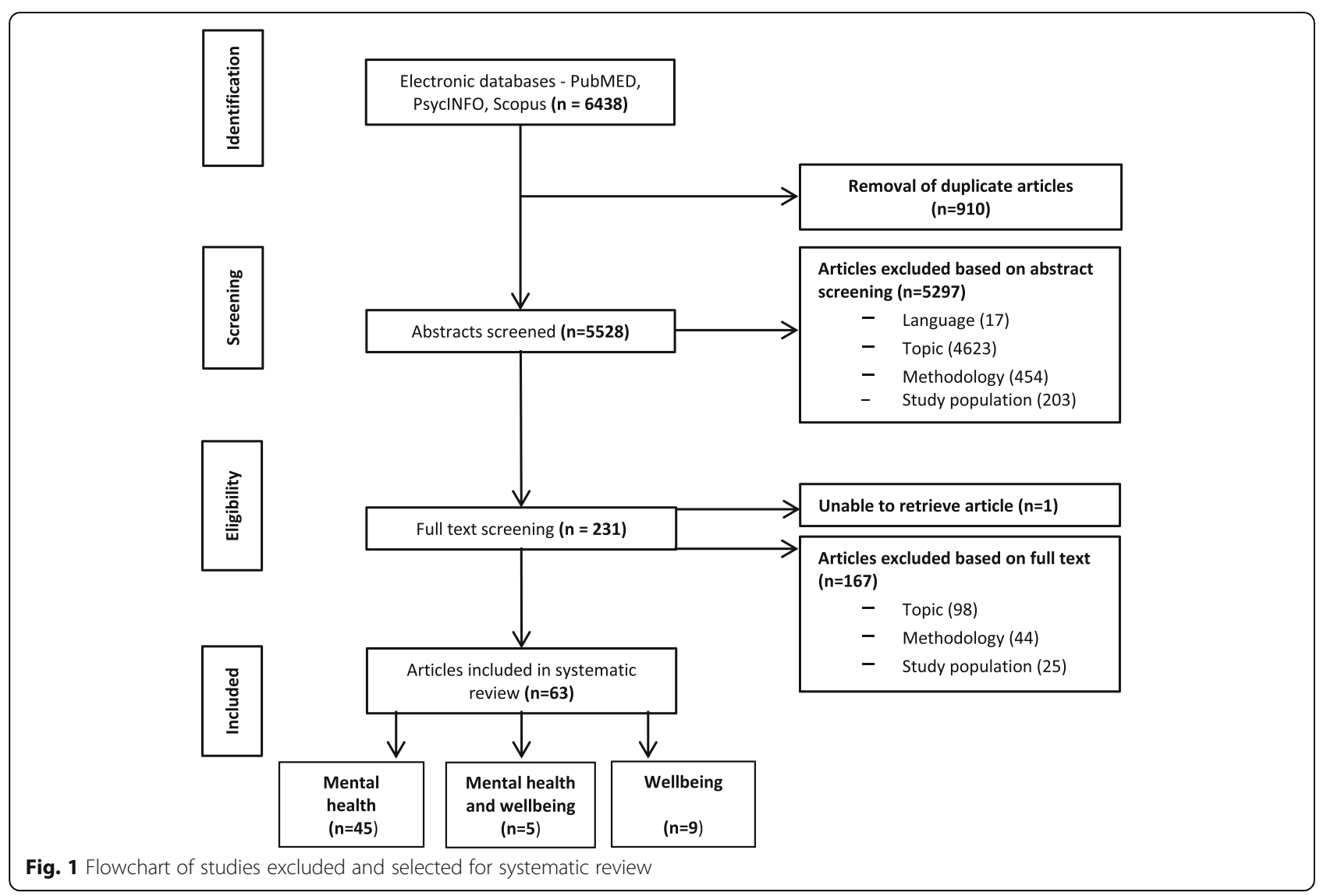

